\title{
Programa razonado del curso de Historia de la Filosofía Moderna.
}

\section{Prop. I.-EL CUADRo HISTORICO EN QUE APARECE LA FILOSOFIA MODERNA}

Para iniciar metódicamente el estudio del pensamiento filosófico moderno es necesario, ante todo, presentar el cuadro histórico en que dicho pensamiento se desarrolla. Primero el escenario, luego la escena. Porque las grandes corrientes del pensamiento no se producen como quisieran los filósofos idealistas--independientemente de los acontecinientos históricos, sino que,como fenómenos de orden superior-por lo mismo que fenómenos-están en relaciones de interdependencia, espacial y temporal, con los otros fenómenos que se adjetivan infraestructurales. Se trata de fenómenos resultantes de los hechos económicos, sociales y políticos. De fenómenos enraizados en la actividad humana perfectamente ponderables por la historia.

De aquí la urgencia de una previa determinación objetiva de la Edad Moderna, particularmente desde el punto de vista económico, tanto para explicar los orígenes y el senticlo de la filosofía moderna como para ofrecer las características 
de conjunto de los lugares,tiempos y situaciones que condicionaron aquella filosofía y que, por otra parte, constituyen los elementos básicos del juicio crítico,

I.a Edad Moderna se singulariza por la aparición y la afirmación del capitalismo. Es la Edad capitalista: la etapa histórica de la sociedad burguesa, del modo de producción burgués, de la política burguesa, del pensamiento burgués.

¿Cómo se operó la transición de la feudalidad a la burguesía? Para dar la respuesta necesaria a esta pregunta se tiene que repetir lugares comunes.

“En la Edad Media - dice Engels- imperaba con carácter general la pequeña industria, basada en la propiedad privada del obrero sobre sus medios de producción: en el campo la agricultura corría a cargo del pequeño campesino, libre o enfeudado; en la ciudad la industria se desenvolvía por medio del traba jo manual de los artesanos". "Hasta el siglo Xdice Aníbal Ponce en su libro "Educación y Lucha de Clases"--las ciudades no podian ser más miserables. Los habitantes eran en su mayoría artesanos y domésticos al servicio de un señor, en condiciones de sumisión idénticas a las de los siervos en la campiña". Renglones más adelante escribe: "Hasta ese momento el señor, que era dueño de la ciudad o burgo, sólo tenía que comprar muy escasos objetos de lujo venidos del Oriente. Los campesinos de sus dominios le traían alimentos y materias primas que los artesanos de su ciudad le trabajaban".

Por lo regular los medios de producción, los productos y el proceso de producción eran individuales. Pero, corridos los años, los productos, destinados al intercambio para la satisfacción de las necesidades individuales, tomaron la forma de mercancías. Entonces la producción y el intercambio no estaban sujetos a plan alguno. Apenas si estaban condicionados 
por una división elemental del trabajo l o que habia de determinar después la anarquía en la producción feudal.

Al lado de las relaciones de producción feudal fueron apareciendo nuevas fuerzas productivas. Las invenciones de la pólvora, del papel, de la imprenta, de la brújula, etc.; los viajes de Marco Polo a la Mongolia y la China : el descubrimiento de América y los demás viajes de exploración de aquella época; el florecimientr, de la industria en las ciudades italianas y el incremento y la extención cada ve matyor del comercio, etc., etc., crearon fuerzas poderosas que determinaron toda una revolución: la revolución burguesa.

A partir del siglo XI el incesante progreso material fué preparando un marcado espíritu de rebeldía contra la injusticia social existente. No puedo resistirme a trascribir el cuadro sombrío de Engels que Ponce consigna en el libro ya citado:

"Sobre los campesinos reposaban todas las otras capas sociales: príncipes, funcionarios, nobleza, clero, patriciado y burguesía. Que perteneciera a un príncipe, a un barón, a un obispo, a un monasterio o a una ciudad, el campesino era tratado en todas partes como una cosa, como una bestia de carga o aún peor. Si era siervo, su dueño disponía a su antojo; si era arrendatario, los préstamos lo aplastaban. La mayor parte de su tiempo debía emplearlo en trabajar las tierras del señor. Con lo que ganaba en sus raras horas disponibles, debía pagar los diezmos, tributos, tasas, viaticum (impuesto militar), impuestos del Estado y tasas del Imperio. No podía casarse ni morirse sin pagar una tasa a su Señor. Además de las prestaciones ordinarias, đebía juntar para el Señor las legumbres y las frutas, la caza y la leña, etc. El derecho de pescar y cazar pertenecía al Señor, y el campesino debía asistir tranquilamente a la destrucción de su cosecha. Las praderas y bosques, que en otro tiempo pertenecieron a las aldeas, les ha- 
bían sido arrebatados por los Señores. Y en igual forma como disponía de la propiedad, el Señor manejaba a su antojo la persona del campesino, de la mujer y de las hijas.Tenía el derecho de pernada, y podia cuando quería encarcelar y torturar a los campesinos".

Tal estado de cosas tenía por fuerza que provocar levantamientos, motines, masacres y excesos de toda índole. Por los siglos XIV y XV las rebeliones tomaron un carácter decisivo. "Son característicos de esta época-dice A.V. Scheglov en su libro "Historia de la Filosofía"-los movimientos populares de masas, que habitualmente tienen lugar bajo la bandera de choques religiosos. Los más grandes de estos movimientos fueron las guerras campesinas en Bohemia (movimiento de los hussitas y los taboritas), la gran guerra campesina en Alemania, en el año r $525 \%$.

Al mismo tiempo que las nuevas fuerzas de producción apareció también un nuero espirítu que đescubrió nuevos horizontes en las diferentes actividades humanas y en los diversos órdenes del pensaniento. Surgió una nueva actitud mental: un nuevo modo de rer las cosas Los hombres, por lo que hace a su conducta ordinaria, fueron abandonando, por ejemplo, el criterio cualitativo en la estimación de las cosas y dando preferencia a !a consideración cuantitativa, propia de la mentalidad burguesa. En el comercio, a la rutina de las transacciones primitivas sucedió la negociación tecnificada a base de contabilidad. Muchas de las cosas, antes estimadas por sus calidades, pasaron a ser consideradas sólo por su valor pecuniario como mercancías.

A lo que vino a agregarse el uso de la moneda. Los artesanos comenzaron a pagar en dinero las retribuciones a los señores y a disponer de cierta libertad para dedicarse al comercio; y los campesinos, por su lado, a pagar las rentas también en dinero y a comprar, en buena cuenta, las famosas cartas 


\section{$-98-$}

por las cuales los señores limitaban su propio poder. El dinero abrió todas las puertas, incluso las de los grandes castillos. "I a ciudad -dice Ponce- se hizo asi un centro de comercio donde los productores cambiaban sus productos. Una profunda transformación arrancó descle alli. Fortalczas hasta ayer, empezaron desde hoy a ser mercado."

Por otro lado, el uso de la pólvora como medio de destrucción vino a completar el proceso de descomposición de! feudalismo. I_as primeras armas de fuego acabaron con los caballeros armados y los castillos-fortalezas. 1.a batalla de Crecy de i 346 fué clemasiado elocuente.

Insurgió un nuevo modo de ser: el caballero trovador, duelista y salteador cle caminos fué suplantado por el taimado hombre de negocios que impuso al mundo el sentido utilitario de la vicla.

$\mathrm{Y}$ se definió un nuevo régimen de producción. Los talleres medievales fueron sustituídos por las fábricas, doncle las necesidades intensivas y extensivas de la producción dieron origen a la división sistemática y organizada del trabajo. Los medios individuales de producción se habían convertido en medios sociales. Pero los instrumentos de producción, las materias primas y los productos se iban concentrancio en pocas manos: eran individuales (pertenecían a los capitalistas); pero la producción era social.

Todos los productos estaban destinados al mercado; psro, igual que en la Edad Media, sin plan ni medida. Y de aquí también la anarquía en la producción burguesa, las crisis ocasionadas por la superproducción y la desocupación.

La producción capitalista divide a la sociedad en proletarios que venden su fuerza de trabajo y en patronos que se apropian de la plusvalía, la acumulan y viven de ella. De aquí, por otro concepto, el antagonismo de clases y la orga- 
nización del poder político (el Estado) como instrumento de dominio de la clase explotadora. Y de aquí, por último, la política clasista, el gobierno clasista. la educación clasista, el pensamiento clasista, etc., con su tremenda secuela de la injusticia social y de la lucha de clases.

A la organización vertical del feudalismo, asentada en la servidumbre, sucedió la organización horizontal de la burguesía que reposa, a su turno, sobre los hombros de la gran masa proletaria de los tiempos modernos.

Este cuadro esquemático de la historia, que constituye el trasfondo material del Renacimiento, da comienzo a la Edad Moderna que se extiende hasta la Contemporánea, Edad ésta caracterizada por la evolución del capitalismo hacia su etapa imperialista.

El pensamiento filosófico, pues, no puede dejar de estar cn estrecha relación con las condiciones materiales de la existencia humana, condiciones que, dicho sea de paso, lo determinan ( I ). Precisamente la filosofía moderna es un producto, una superestructura, de las condiciones económicas, políticas y sociales que se desarrollaron bajo el signo del capitalismo a partir del Renaciniento. Al respecto dice Engels: "Del mismo mođo que toda la época del Renacimiento, desde mediados del siglo XV, fué un producto esencial de las ciudades $y$, por

(1) Para reforzar la tesis que sostengo trascribo a continuación de la página 312 del libro "Materialismo Dialéctico" de Emilio Troise el siguiente párrafo:

"Sólo a mancra de ejemplos ilustrativos mencionaremos la relación intima entre la filosofía materialista jónica y la vida activa, industrial y comercial de la ciudades del Asia Menor, en la Grecia antigua; entre la diláctica de Heráclito $\mathrm{y}$ su condición de aristócrata fundiario cuya clase habia sido desplazada $y$ dominada por una clase comerciante combativa $y$ aven. turera; entre la filosofía escolástica de la Edad Media y la estructura feudal de dicha época; entre el materialismo de Bacon $y$ el desarrollo de la burguesía inglesa; entre el materialismo francés de fines del siglo XVIII $y$ el ascenso revolucionario de una clase que so preparaba a organizar definitivamente su mundo; entre el idealismo místico actual y la crisis profunda que el régimen capitalista sufre después de la guerra imperialista de 1914". 
consigujente, cle la burguesía, la filosofia despertó a partir de aquella época. Su contenido no era, en el fondo, sino la expresión filosófica che las icleas correspondientes a la etaja del clesarrollo que va de la pequeña y cle la media burgruesía a la gran burguesia".

\section{Prop. II.-EL RENACIMIENTO_-FUMANISMO $Y$ RENACIMIENTO}

El pensamiento en la Edad Meclia estuvo subordinaclo at la Iglesia. La obsesión teológica y el criterio de autoridad habian estableciclo su doninio absoluto en los preblos cultos de entonces. "La religión- escribe F. Sherwood Taylor en su "Breve Historia de la Ciencia"- - se habia arrogado el derecho de decielir a trayés de la antoridad de ios Padres de la Iglesia y de las Sagradas Escrituras accrca de todas las cuestiones, ya fuesen teológicas, morales o cientificas. El universo era una jerarquia en la cual el seglar carecia cle puesto".

La escolástica informaba la estructura del pensamiento que podemos llanar oficial. Filósofos y teólogos se a fanaban en fundamentarorabionalnente los dogmas y en claborar sistemas del iniverso que se acomodaran a la ortodoxia católica.

Pero, con el tiempo, en el stbsuelo de aquella culturaque tenía por realidarl primaria el mundo celestial y por realiclad secunclaria el murnto pecaminoso que pisamos-se clisponian, al par que nuevas fuerzas de producción, nuevas fuetzas espirituales fue, a la larga o a la corta, habian de romper la estructura devenicla, remuática y anquilosada del pensamiento feuclal. Contra el espiritu monacal y ascético del medievo irrumpió una tendencia mundanal y eufórica. La observación y la experiencia dieron al traste con el principio de antoridad. 
En la Edad Media la cultura se había refugiado en los conventos. Pese a la vida de retiro y de mortificaciones de los anacoretas, cenobitas y ascetas los monasterios absorbieron el saber antiguo $\mathrm{y}$, mediante sus Padres, doctores y clérigos sobresalientes, asumieron la dirección espiritual del medioevo.

Pero los monjes, en la segunda mitad de la Edad Media, con la relajación de sus costumbres, habían renunciado a li contemplación y olvidado las bibliotecas. En vista de los nuevos accintecimientos, precursores de una transformación inminente, poco seguros de su posición ideológica, incursionaban en el mundo de las tentaciones a saborear los goces de los sentidos. Los profanos, por su parte, llenos de experiencia herética, que habían comenzado a poner en tela de juicio las verclades reveladas, viendo que los depositarios del saber se mundanizaban, invadian las bibliotecas de los conventos y cultivaban el saber por su cuenta. Este fenómeno de ósmosis que se verificaba entre clérigos y seglares trajo como consecuencia la vulgarización de la cultura y el despertar dei individualismo moderno. con desmedro, claro está, cle la autoriclad eclesiástica.

"I.a dictadura de la iglesia estaba rota-dice Shcheglov-. Los intereses seculares y la vida terrena llena de vitaliclad se oponían ásperamente al ascetismo feudal, a la atmósfera sofocante de la iglesia y al mundo ilusorio del "más allá". I.a personalidad humana, viva y de múltiples y variados aspectos, que rompia las cadenas del régimen de servidumbre, se transformó en el centro de atención".

No obstante, la clerecía y la nobleza se esforzaba por conservar el sentido teológico-caballeresco decadente, apoyados no ya en el saber y el valor, sino únicamente en el res- 
peto que merecian la autoridad de la Iglesia y los rangos nobiliarios. Los comerciantes e industriales, de origen generalmente plebeyo, que veian crecer su poder y su importancia con el incremento del capitalismo, fueron organizando un mundo moral e intelectual nuevo que debía suplantar al munclo envejecido de los señores y monseñores. Operado, pues, el fenómeno de la mundanización de la clerecía y la culturización de la burguesía, el nuevo pensamiento filosófico volvió los ojos al mundo y la vida, al mundo de los hombres de carne y hueso, relegando a un segundo término el mundo de los dioses.

La cultura de la Edad Media era teocéntrica. El objeto primero del conocimiento era Dios. La cultura del Renacimiento devino geocéntrica; y mas aún, homocéntrica. Humanista.

Roger Bacon, "el padre de la ciencia experimental moderna", como lo califica H. G. Wells, al combatir la docta ignorancia de las gentes solemnes, los dogmas y las autoridades tradicionales, inauguró, al propio tiempo el método experimental. Desdel entonces el conociniento tuvo que elevarse de la expériencia a da ley, yono a la inversa, como ocurría durante el međioevo, y durante casi toda la antigiiedad. Para Arquímedes eran indignos de recordación los mecanismos que construyó. Según él únicamente los principios abstractos generales constituían el objeto digno de la filosofía. Pero, a partir del Renacimiento todo conocimiento, para ser válido, tiene que brotar de la experiencia (de la experiencia interna y externa). Galileo, con su método científico, se colocó, pues, en la antípoda de Arquímedes.

La filosofía, atenta a las insinuaciones de la ciencia empírica, acabó por acercarse al hombre y al mundo. Acabó por considerar indispensables los datos últimos de la ciencia. 
Desde el punto de mira estrictamente religioso, como advierte José Ortega y Gasset en sus "Ensayos", el proceso del Renacimiento of rece un cambio notable: Si durante la Edad Media el hombre vivía prendido de Dios, ahora es Dios cl que vive prendiclo del corazón del hombre. Dios ya no está en el trasmundo trascendente, inabordable e incognoscible, sino en el mundo vivo e inmanente de la fé que se cobija en cl corazón del hombre. Se ha operado el fenómeno doble de la valorización de lo humano y la humanización de lo divino. Ortega y Gasset propone como ejemplo la "devotio moderna" que arranca de la "Imitación de Jesucristo" de Kempis.

El clespertar espiritual de los siglos XIV y XV, que $\epsilon n$ general se conoce con el nombre de Renacimiento, para deshacerse del peso asfixiante de la autoridad eclesiástica, buscó asicleros en la cultura más inmediata: en la cultura clásica. Los hombres de estudio de los siglos indicados, empeñados en el jadeo liberatorio, no tuvieron el tiempo, la disposición y los elementos necesarios para crear acto seguido una cultura nueva en sustitución de la teológicà del medioevo. $Y$ de aquí que, por una especie de instinto de conservación y de un impulso natural de expansión, buscaran asidero en la cultura greco-romana, cultura efectivamente humana que mezclaba hasta a sus clioses en las controversias e intereses terrenos de los hombres.

Pero el Renacimiento en ningún caso comporta una simple vuelta al pasado clásico, porque la historia, según veredicto universal, es irreversible. Si ningún hecho histórico puede repetirse exactamente y menos reactualizarse en esencia, siguiendo el principio de la identidad, toda vuelta histórica resulta imposible. En este sentido, la misma actitud de rebeldía de los hombres del Renacimiento contra la cultura estagnada de la Edad Media constituía ya un avance en el 
decurso de la historia, y no una vucita. Una cosa es que los artistas y pensadores renacentistas votrienom los ojos a la cultura greco-romana, para conocerla a fondo e inspirarse en ella, y otra muy distinta el qute pudiena haluer remuch ce ar. te $y$ el pensamiento griegos y latinos por efecto de un sortilegio anacronista. El entusiasmo de los artisias y petsiadores del Renacimiento por la cultura pagana era oblicuo, como asevera Ortega y Gasset, porque diche entustasmo era súlu un medio de deshacerse de las relacioncs de prodtucción intelectual (y que valga la expresion ) del feudalistuso: de los dormas y de la autoridad de la Iglesia. Era únicamente un medio y no un fín. "I a burgtresia--sostiene Shcheglow-luscal 'a herencia de la sociedad antigta, contraponiendola a la ideolngía feudal-eclesiástica. El estudio esforzadr de los grandes originales del pensamiento y del arte antigtios ingi el pápel principal en la creación de la nueva cultura. Dc acquí el término Renacimicnto, en el sentido de la resurrección de lia antigua cultura que no agota, ni mucho menos, clatio está, ei contenido de la época".

De acuerdojcon Prtega yl Gassete es preciso hacer una distinción muy sugestiva entre Humanismo y Renacimiento. términos que hasta hace poco han sido generalmente tomados como sinónimos. El Humanismo, fenómeno cultural del siglo XIV y parte del XV, es la "vuelta" a la cultura grecolatina (el neoplatonismo y el neoaristotelismo, por ejemplo) y al cristianismo primitivo (Petrarca), donde se encuentra al hombre en su grandeza clásica. Al hombre, sencillamente, como objeto fundamental de estudio, como protagonista de la historia, en el foco de la atención filosófica. Implica el abandono de la cultura teocéntrica del medievo para reinaugurar la ctaltura homocéntrica de la antigüedad preescolástica. "La innitación de Cristo" que, como repetimos, suscita 
la "derotio moderna", traslada al Dios suprarracional de la región insondable del cielo a la zona palpable del sentimiento humano. Entonces Dios se encarna en el hombre y baja a la tierra como bajaban los dioses del Olimpo al suelo heleno.

A tal reencuentro del hombre pagano, en la cultura clásica y en la ingenua religión cristiana primitiva, ha dado Ortega y Gasset en llamar Humanismo

El renacimiento-en su acepción más propia y restringida-, fenómeno de los siglos XV y XVI y parte del XVII, es una "vuelta" al pasado más remoto: a la precultura (Montaigne, Rousseau, Descartes), donde se descubre al hombre en estado de naturaleza. Al hombre despojado de todo lastre cultural (de la cultura medieval y pagana); al hombre puro sin pecado cultural, al hombre que ha de encontrarse a sí mismo en estado de pureza originaria. $\mathrm{Y}$ este hombre que ha de emprender la creación de un arte y de un pensamiento inéditos, totalmente nuevos, ha de ser el hombre que re-nace. De aquí el sentido del Renaciniento propiamente dicho. Pero el Renacimiento es, por lo mismo, la afirmación del presente con preferencia al pretérito (Descartes).

Pero el Renacimiento, ya lo hemos dicho, no es sólo un acontecimiento superestructural, meramente artístico y cultural. Es también, y ante todo, un movimiento de transformación económica, social y política. Si recordamos únicamente estos dos hechos: I. ${ }^{\circ}$, que la gran jerarquía seglar de castellanos, barones, vizcondes, condes, marqueses, duques y reyes abrumaba a las masas de villanos y siervos con tributos excesivos, y $2^{\circ}$, que la gran organización eclesiástica, en el orden económico y financiero (pues que "los monasterios fueron a lo largo de la Edad Media instituciones bancarias de crédito rural"-Ponce) extorsionaba no sólo a las desorganizadas masas campesinas, sino también a los necesitados nobles y. 


\section{$-106-$}

príncipes prestatarios, se comprenclerá que la época tenía un gran contenido de lucha de clases. Y se comprenderá igualmente que el Renacimiento-tomado este término en su acepoirin más lata-importaba la fermentación de un vasto movimiento de liberación social y politica, y no solamente cultural. Mainuel Serra Moret escribe en "Los Fundamentos de la Historia y la Filosofía" sobre el particular, aunque con criterio más restringido, lo siguiente: "La verdadera lección del Renacimiento es ésta: que no hay ni puede haber realización cultural si no se parte de la base, si no se cambia de actitud, si no existe en el hombre la estimación de si mismo, si no se acepta el principio moral del deber equiparado al derecho y de que a cada uno corresponde una tarea, igualmente digna, igualmente importante, sea de orden intelectual o de orden manual, directiva o simplemente ejecutiva. El trabajo nos lleva a amar la libertad porque sin libertad no hay trabajo, que es, contra lo que algunos opinan, lo que más absorve al hombre y lo que más estima. Y, como todas las revoluciones profundas, el Renacimiento fué esto: una gran fiebre de trabajo y un denodado esfuerzo de liberación"'. (Entendemos que Scrra Moret se refiere al trabajo creador, de mayor rendimiento, del hombre libre).

El Renacimiento es,pues, el primer acto de la revolución burguesa.

Antero Peralta VízQuez. 